\title{
Propagation of the Hydraulic Head in an Elastic Pipeline
}

\author{
Blanka Filipová, Pavel Nevřiva, Štěpán Ožana \\ VSB - Technical University of Ostrava, 17. listopadu 15, Czech republic \\ \{blanka.filipova, pavel.nevriva, stepan.ozana\}@vsb.cz
}

\begin{abstract}
This paper deals with the measurement and simulation of the dynamic processes on the systems with distributed parameters. As an example of such a system the elastic pipeline transporting the elastic fluid has been chosen. The effort was mainly aimed at the measurement and modeling of prime hydraulic head in the pipeline which arises after sudden closing the valve. The problem described here can be considered as signals and systems analysis because we actually look for an output signal of the system that transforms the input signal. Finally the measured and simulated data are compared and their correspondence was evaluted.
\end{abstract}

\section{Physical Model of the System}

Physical model of the system is shown on Fig. 1. It composes of the pipeline, pressure sensors and valve. The measured part of the pipeline is the part of pipeline between pump and valve. Measured quantities were the pressures in points $\mathrm{P} 1$ and $\mathrm{P} 2$. After closing the valve the moving water column starts the dynamic process.

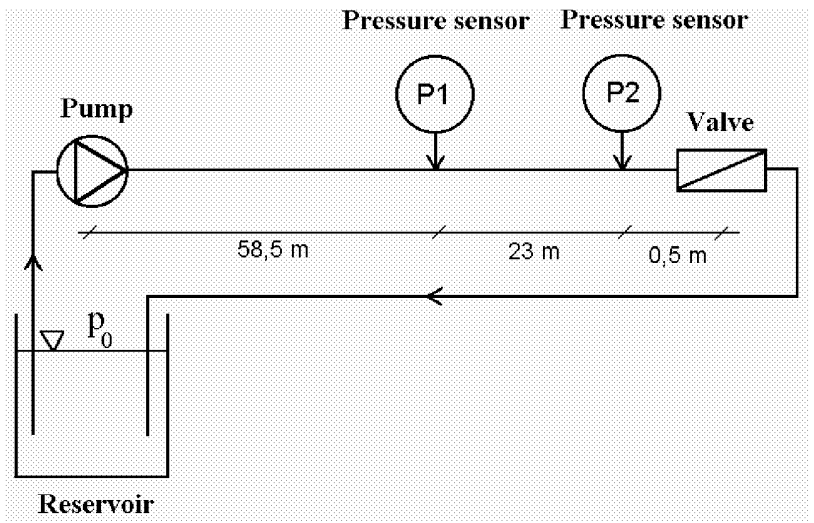

Fig. 1. Schema of the laboratory system. 


\section{Setting up the Mathematical Model}

The model below describes flowing of the elastic fluid in the segment of elastic pipeline. The original mathematical model is described by three nonlinear partial differential equations of the first order. The fundamental of the model consists of Newton equation (1), Equation of continuity (2) and Bernoulli equation (3). The model is extended by equations (4) and (5) with respect to the elasticity of pipeline and transferred fluid.

- Newton equation

$$
\frac{\partial p}{\partial x}+\rho v \frac{\partial v}{\partial x}+\rho \frac{\partial v}{\partial t}+\rho g \frac{\partial z}{\partial x}+\frac{\lambda \rho v|v|}{2 d n}=0
$$

- Equation of continuity

$$
\begin{aligned}
\rho S \frac{\partial v}{\partial x} & +\rho v\left(\frac{\partial S}{\partial p} \frac{\partial p}{\partial x}+\frac{\partial S}{\partial T} \frac{\partial T}{\partial x}+\frac{\partial S}{\partial x}\right)+S v\left(\frac{\partial \rho}{\partial p} \frac{\partial p}{\partial x}+\frac{\partial \rho}{\partial T} \frac{\partial T}{\partial x}\right)+ \\
& +\rho\left(\frac{\partial S}{\partial p} \frac{\partial p}{\partial t}+\frac{\partial S}{\partial T} \frac{\partial T}{\partial t}\right)+S\left(\frac{\partial \rho}{\partial p} \frac{\partial p}{\partial t}+\frac{\partial \rho}{\partial T} \frac{\partial T}{\partial t}\right)=0
\end{aligned}
$$

- Bernoulli equation

$$
\frac{\partial}{\partial t}\left(\rho\left(c \mathrm{~T}+\frac{\mathrm{v}^{2}}{2}\right)\right)+\frac{\partial}{\partial \mathrm{x}}\left(\rho \mathrm{v}\left(\mathrm{c} \mathrm{T}+\frac{\mathrm{v}^{2}}{2}\right)\right)+\frac{\partial(\mathrm{p} \mathrm{v})}{\partial \mathrm{x}}+\frac{\partial(\rho \mathrm{vg} \mathrm{z})}{\partial \mathrm{x}}-\frac{\gamma\left(\mathrm{T}_{\mathrm{ok}}-\mathrm{T}\right)}{\mathrm{S}}=0
$$

- Additional equations for density and cross-section:

$$
\begin{gathered}
\rho=\frac{\rho_{0}}{\exp \left(\frac{1}{\mathrm{~K}}\left(\mathrm{p}_{0}-\mathrm{p}\right)\right) \exp \left(\beta\left(\mathrm{T}-\mathrm{T}_{0}\right)\right)} \\
\mathrm{S}=\mathrm{S}_{0} \exp \left(\frac{\mathrm{dn}}{\mathrm{Ed}}\left(\mathrm{p}-\mathrm{p}_{0}\right)\right) \exp \left(2 \alpha\left(\mathrm{T}-\mathrm{T}_{0}\right)\right)
\end{gathered}
$$


where

$\begin{array}{lll}\mathrm{c} & = & \text { internal energy of liquid } \\ \mathrm{d} & = & \text { wall thickness of the pipeline } \\ \mathrm{dn} & = & \text { internal diameter of the pipeline } \\ \mathrm{E} & = & \text { modulus of elasticity } \\ \mathrm{g} & = & \text { acceleration of gravity } \\ \mathrm{K} & = & \text { liquid elasticity bulk modulus } \\ \mathrm{l} & = & \text { length of pipeline } \\ \mathrm{p} & = & \text { pressure of liquid } \\ \mathrm{p}_{0} & = & \text { relative pressure } \\ \mathrm{S} & = & \text { cross sectional area of the pipeline } \\ \mathrm{S}_{0} & = & \text { relative cross sectional area of the pipeline } \\ \mathrm{t} & = & \text { time } \\ \mathrm{T} & = & \text { temperature of liquid } \\ \mathrm{T}_{\mathrm{ok}} & = & \text { ambient temperature } \\ \mathrm{T}_{0} & = & \text { relative temperature } \\ \mathrm{v} & = & \text { flow velocity of liquid } \\ \mathrm{x} & = & \text { coordinate along pipeline axis } \\ \mathrm{z} & = & \text { elevation of the pipeline } \\ \alpha & = & \text { bulk expansivity of pipeline } \\ \beta & = & \text { bulk expansivity of liquid } \\ \gamma & = & \text { heat transfer coefficient } \\ \lambda & = & \text { friction factor of liquid } \\ \rho & = & \text { density of liquid } \\ \rho_{0} & = & \text { relative density of liquid } \\ & & \end{array}$

The original mathematical model was adapted for the laboratory system. The temperature processes were omitted, they would be significant mainly in pipeline with a gas or with a steam.

The mathematical model was therefore modified as follows:

$$
\begin{gathered}
\frac{\partial p}{\partial x}+\rho v \frac{\partial v}{\partial x}+\rho \frac{\partial v}{\partial t}+\rho g \frac{\partial z}{\partial x}+\frac{\lambda \rho v|v|}{2 d n}=0 \\
\rho S \frac{\partial v}{\partial x}+\rho v\left(\frac{\partial S}{\partial p} \frac{\partial p}{\partial x}+\frac{\partial S}{\partial x}\right)+S v\left(\frac{\partial \rho}{\partial p} \frac{\partial p}{\partial x}\right)+\rho\left(\frac{\partial S}{\partial p} \frac{\partial p}{\partial t}\right)+S\left(\frac{\partial \rho}{\partial p} \frac{\partial p}{\partial t}\right)=0
\end{gathered}
$$


Appropriate equations for density and cross-section were modified, too:

$$
\begin{gathered}
\rho=\frac{\rho_{0}}{\exp \left(\frac{1}{K}\left(p_{0}-p\right)\right)} \\
S=S_{0} \exp \left(\frac{d n}{E d}\left(p-p_{0}\right)\right)
\end{gathered}
$$

In order to find a unique solution of set of equations (6)-(9), the boundary and initial conditions must be added.

These are as the follows:

The boundary conditions:

- The velocity in the end of the pipeline - in the point where the valve is placed. After closing valve the velocity of the water in this point is $\mathrm{v}=0$.

- The pressure in the beginning of the pipeline - in the point where the pump is placed. This pressure is described by load characteristic of the pump, see Fig. 2.

The initial conditions:

- The distribution of the pressure within the whole length of the pipeline, this was linearly interpolated of the measured pressures P1, P2. The distribution of the pressure within the whole length of the pipeline is shown on Fig. 3.

- The distribution of the velocity within the whole length of the pipeline. The velocity in $\mathrm{t}=0$ was constant and equals to $\mathrm{v}=1.66 \mathrm{~m} \cdot \mathrm{s}^{-1}$.

- The distribution of the elevation within the whole length of the pipeline. The derivative of the elevation equals to zero, because the pipeline was rolled up horizontally.

- The distribution of the cross-section within the whole length of the pipeline. The cross-section in time $\mathrm{t}=0$ is constant, $\mathrm{dn}=0,032 \mathrm{~m}$. 


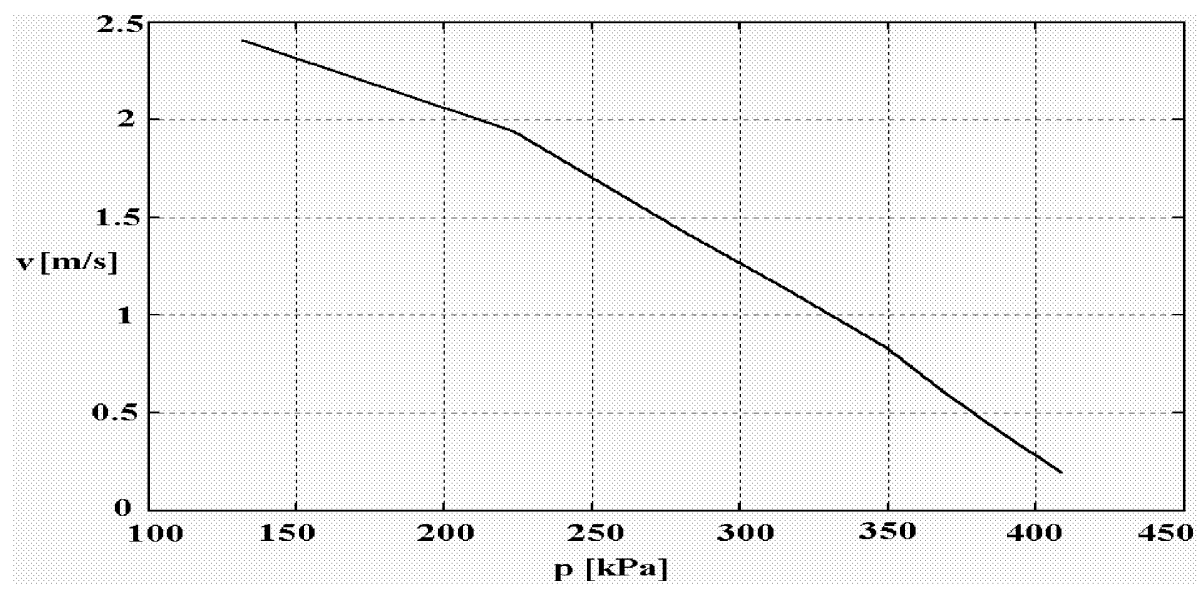

Fig. 2. The load characteristic of the pump

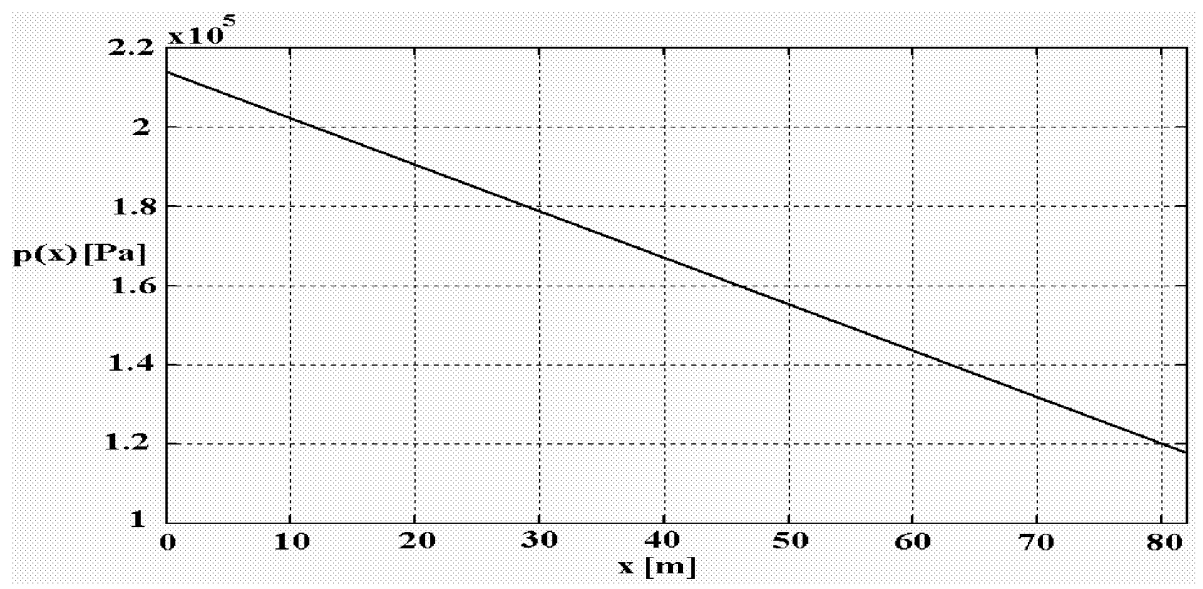

Fig. 3. The distribution of the pressure within the whole length of the pipeline.

\section{Simulation of the Model}

The system of the equations (6) - (9) was solved using the numerical methods, particularly the method of final differences and method of Adams Bashforth. Simulation was performed using MATLAB.

Here only the first step of setting up a Matlab code will be shown. It is the idea to express the terms $\frac{\partial v}{\partial t}$ and $\frac{\partial p}{\partial t}$ from equations (6) and (7). 


$$
\begin{gathered}
\frac{\partial v}{\partial t}=-\frac{\lambda v|v|}{2 d n}-\frac{\partial z}{\partial x}-v \frac{\partial v}{\partial x}-\frac{1}{\rho} \frac{\partial p}{\partial x} \\
\frac{\partial p}{\partial t}=\frac{\rho S \frac{\partial v}{\partial x}+\rho v\left(\frac{\partial S}{\partial p} \frac{\partial p}{\partial x}+\frac{\partial S}{\partial x}\right)+S v\left(\frac{\partial \rho}{\partial p} \frac{\partial p}{\partial x}\right)}{\rho \frac{\partial S}{\partial p}+S \frac{\partial \rho}{\partial p}}
\end{gathered}
$$

Terms are integrated using Adams-Bashforth method of the $4^{\text {th }}$ order.

\section{Measurement on the System}

\subsection{Auxiliary Measurement of Modulus of Elasticity}

The modulus of elasticity was determined by equation (5). The effect of temperature was eliminated, therefore

$$
E=\frac{d n\left(p-p_{0}\right)}{d \ln \frac{S}{S_{0}}}=\frac{d n\left(p-p_{0}\right)}{d \ln \frac{V_{0}+\Delta V}{V_{0}}}
$$

where $V_{0}=3 \pi \mathrm{dn}^{2}$ is initial volume at initial pressure. Measuring procedure: there is the controlled source of pressure at the beginning of the pipeline. At the opposite end there is an outlet valve and pressure sensor. The pipeline of the length of 3 meters was pressured and the differences $\Delta \mathrm{V}$ of its volume were measured.

Two sets of measurements were performed:

- The pipeline was always pressured from initial pressure $p_{0}$ to maximal value of $560 \mathrm{kPa}$.

- The pipeline was progressively pressured from initial pressure $p_{0}$ to maximal value in 10 steps of about $56 \mathrm{kPa}$. 
The modulus of elasticity was determined in range of $\mathrm{E}=0.99 \cdot 10^{7} \div 1.45$. $10^{7} \mathrm{~Pa}$.

\subsection{Measurement of Hydraulic Head and Its Comparison with Simulated Data}

The measuring of the hydraulic head is performed on the measuring system from Fig. 1. At first the valve is open and water flows in pipeline. Then the valve is suddenly closed and the hydraulic head arises. The propagation of the hydraulic heads in places P1 and P2 and its comparison with simulated data is presented on Fig. 4 and Fig. 5.

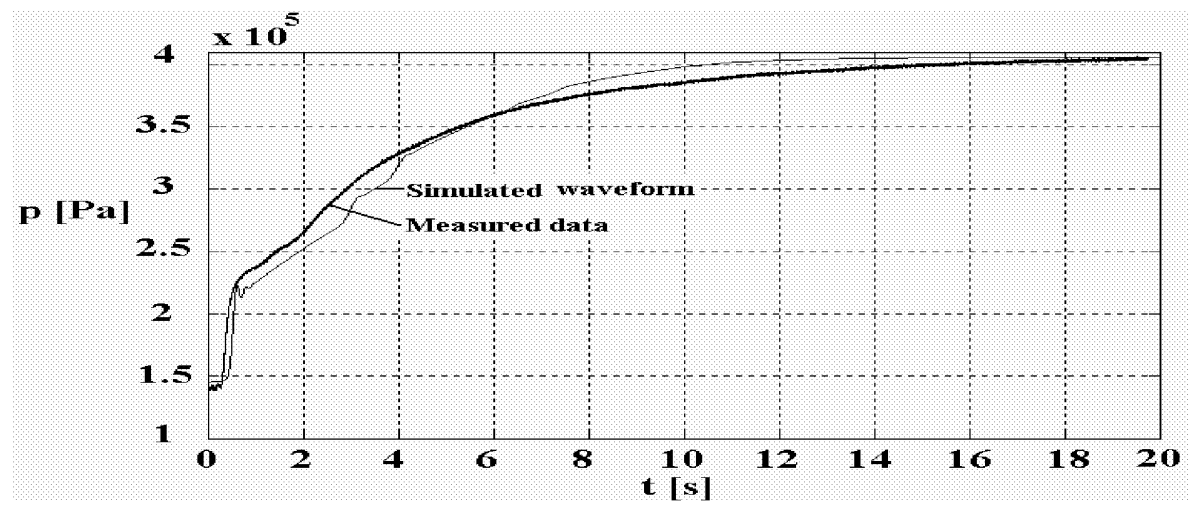

Fig. 4. Comparison of the measured and simulated data in point P1.

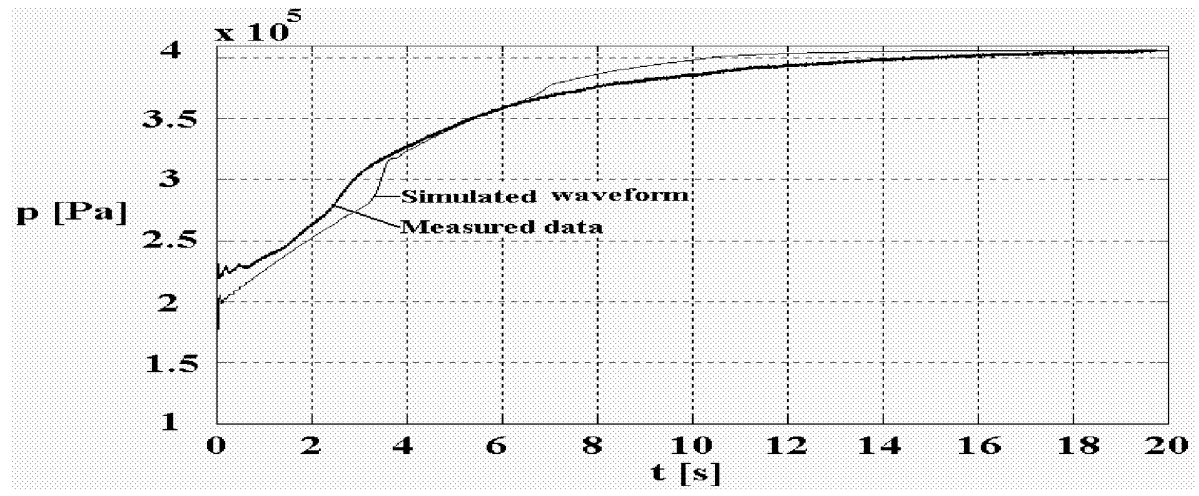

Fig. 5. Comparison of the measured and simulated data in point P2. 


\subsection{The Evaluation of the Mathematical Model}

For the evaluation of the mathematical model the mean quadratic criterion was used. The following loss function is minimized:

$$
J=\frac{1}{n} \sum_{i=1}^{n}\left|\left(y_{i, \text { ref }}-y_{i}\right)\right|^{2}
$$

where $y_{i}$ are values of quantity which are refereed to reference values $y_{i, r e f}$. For measuring point $\mathrm{P} 1$ the computed value is $\mathrm{J}=9,9 \cdot 10^{7}$, for measuring point $\mathrm{P} 2$ the computed value equals to

$\mathrm{J}=1,068 \cdot 10^{8}$.

\section{Conclusion}

The measurement of the pipeline expansion verified the hypothesis that equation (9) is not convinient for the material of the pipeline used in this project, one of the further aims is to find more adequate formula for its expansion.

The simulation proved that the model is very sensitive to the modulus of elasticity of the used material which has some non-linearities and other dynamic qualities. Therefore the subsequent aim of the poject is to explore and include these dynamic qualities to the current model. The heuristic method was used to simulate such a situation and it leaded to interesting results. These results were evaluated by the same mean quadratic criterion and the loss function reached ten times smaller values than originally.

\section{References}

1. Demčáková, B., Nevřiva, P.: Control of the Flow Rate in an Outflow line. $15^{\text {th }}$ IFAC World Congress. Barcelona, Spain 2002.

2. Filipová, B.: Modelování a regulace rázu pružného média v pružném potrubí. Dissertation. Ostrava, 2002.

3. Ožana, Š.: Měření dynamických jevů na soustavách tvořených pružnými potrubími. Thesis. Ostrava, 2002. 